\title{
Sala Verde Paraíba do Sul: avanços e perspectivas.
}

\section{Green Room Paraiba do Sul: progress and prospects.}

${ }^{1}$ Francisco Jácome Gurgel Júnior gurgel.j@@gmail.com

${ }^{2}$ Ana Carolina Callegario Pereira

${ }^{3}$ Cirlene Fourquet Bandeira

${ }^{3}$ Shane Soares Goulart

${ }^{4}$ Anna Paula Oliveira Santos

\section{RESUMO}

O artigo em tela tem por objetivo informar o processo de criação da Sala Verde Paraíba do Sul instalada nas dependências de um Centro Universitário localizado em Volta Redonda/RJ, suas peculiaridades, fragilidades e potencialidades, bem como elencar as atividades desenvolvidas pela mesma desde o início de suas atividades até os dias atuais, destacando os projetos de educação ambiental de caráter formal e não-formal em curso e aqueles concretizados que se consubstanciam em palestras, oficinas, participação em eventos, seminários, visitas orientadas, reuniões de trabalho, cooperação com órgãos públicos, instituições de ensino, capacitação, produção de material didático, etc. Pretende-se também destacar a importância da mesma como espaço socioambiental privilegiado para a difusão da Educação Ambiental na cidade e adjacências e seu papel auxiliar na formação acadêmica dos alunos dos cursos de graduação em Engenharia Ambiental, Engenharia Civil, Engenharia de Produção, Engenharia Elétrica, Ciências Biológicas, Design e Sistemas de Informação. A pesquisa visa supletivamente aferir se a sala em questão tem atingido seus objetivos maiores conforme especificado no edital do Departamento de Educação Ambiental subordinado ao Ministério do Meio Ambiente como lócus socioambiental que além do acesso à informação, ofereça a possibilidade de reflexão e construção do pensamento/ação ambiental e perspectivas para um futuro mais sustentável.

Palavras-chave: Sala Verde Paraíba do Sul, Educação Ambiental, Volta Redonda, Sustentabilidade Ambiental.

\section{ABSTRACT}

Article screen aims to inform the process of creating the Green Room Paraiba do Sul installed on the premises of a University Center located in Volta Redonda / RJ, its peculiarities, weaknesses and strengths, as well as list the activities carried out by him from the beginning of their activities to the present day, highlighting the environmental education projects of formal and non-formal ongoing and those implemented that are embodied in lectures, workshops, participation in events, seminars, guided tours, workshops, cooperation with agencies public, educational institutions, training, courseware production, etc. It also aims to highlight the importance of it as a privileged social and environmental space for the dissemination of environmental education in the city and surrounding areas and its auxiliary role in the academic education of students in undergraduate courses in Environmental Engineering, Civil Engineering, Production Engineering, Electrical Engineering, Biological Sciences, Design and Information Systems. The research aims complementarily assess whether the room in question has achieved its major objectives as specified in the Department of Environmental Education of the notice under the Ministry of Environment as environmental locus that in addition to access to information, offer the possibility of reflection and construction of thought / environmental action and perspectives for a more sustainable future.

Keywords: Green Room Paraiba do Sul, Environmental Education, Volta Redonda, Environmental Sustainability.

\footnotetext{
1 Docente do Centro Universitário de Volta Redonda (UniFOA); Docente da Secretaria Estadual de Educação do Rio de Janeiro/SEEDUC-RJ.

2 Coordenadora e professora do curso de Engenharia Ambiental do Centro Universitário de Volta Redonda (UniFOA).

Professora do curso de Engenharia Ambiental do centro Universitário de Volta Redonda (UniFOA).

Aluna do $7^{\circ}$ período do Curso de Engenharia Ambiental do Centro Universitário de Volta Redonda (UniFOA).
} 


\section{INTRODUÇÃO}

A Sala Verde Paraíba do Sul, objeto deste estudo está instalada à Avenida Paulo Erlei Alves Abrantes, n ${ }^{\circ} 1325$, bairro Três Poços, município de Volta Redonda, Campus Olezio Galotti, abrigada na sala 405, $3^{\circ}$ andar do prédio 18 que abriga o curso de graduação de Engenharia Ambiental do Centro Universitário de Volta Redonda (UniFOA). Em Volta Redonda, cidade do Sul Fluminense, localizada no vale do Médio Paraíba, entre a Serra do Mar e a Serra da Mantiqueira, com 242 mil, 063 habitantes, sede da maior usina siderúrgica da América Latina, terceira maior receita fiscal do estado e que abriga 4.829 empresas atuantes (www.portalvr.com, 2016), a gestão ambiental e a educação ambiental de caráter formal e informal assumem importância ímpar, pois, como município mais importante da região sul fluminense e polo metal-mecânico de relevância nacional, os recursos ambientais descritos pela lei da Política Nacional do Meio Ambiente (Lei Federal $n^{0}$ 6.938/81) estão sempre expostos a poluição atmosférica abundante gerada principalmente pela Companhia Siderúrgica Nacional (CSN). A expansão urbana desordenada das encostas que circundam o perímetro municipal e o vale aluvional, o despejo ilegal, elevado e constante de efluentes industriais no rio Paraíba do Sul por diversas indústrias instaladas na bacia, o desmatamento incontido dos "mares de morros" antes recobertos por vegetação nativa de Mata Atlântica (Ab’ Saber, 2003) e a contaminação do solo, subsolo e corpos hídricos provocados pela ausência de um aterro sanitário são outros impactos negativos pontuais de relevância que corroboram para a degradação ambiental do meio urbano e rural na maior cidade da região Sul Fluminense. A criação de uma sala verde na cidade do aço pode e deve contribuir decisivamente para a formação de um cidadão voltarredondense mais consciente, ativo e participativo nagestão ambiental de caráter público. A sala verde em questão tem 23,24 $\mathrm{m}^{2}$ de área total, capacidade para cerca de 30 pessoas sentadas e conta com a seguinte infraestrutura: internet (via cabo e wi-fi), estantes para acondicionamento de material didático, dois computadores, três mesas, quatro cadeiras, um armário, uma impressora, um Data-Show, um quadro-branco, um aparelho de ar-condicionado do tipo Split com controle remoto e infraestrutura física adequada a realização de "mesas redondas”, palestras, minicursos e workshops conforme se observa parcialmente na figura 02. A sala verde conta com o apoio de quatro docentes e quatro discentes da própria instituição e uma auxiliar de biblioteca responsável pela organização e manutenção do acervo sob a orientação da bibliotecária institucional. O início do projeto Sala Verde é fruto de efetiva e sinérgica parceria de alunos e professores do curso de Engenharia Ambiental que sabedores da existência do edital do Ministério do Meio Ambiente (MMA) sob a égide do Departamento de Educação Ambiental (DEA) que dispõe sobre a criação destes espaços socioambientais, mobilizaram-se e com o apoio da reitoria formularam o projeto político-pedagógico, exigência do processo de seleção, assim como o documento comprobatório das atribuições legais e finalidade precípua da instituição proponente, decreto e ata de criação, estatuto, regimento ou outro; cópia autenticada do CPF; cédula de identidade do representante legal e ficha de identificação on-linee submeteram os mesmos ao processo de seleção intitulado Edital n 01/2013 “Projeto Salas Verdes”. O Projeto Político Pedagógico da Sala Verde Paraíba do Sul (Figura 01) ora submetido pauta-se no objetivo geral de se criar um espaço democrático, com o desenvolvimento de atividades de cunho socioambiental visando integrar a comunidade acadêmica à sociedade civil, possibilitando que todos os participantes atuem ativamente na gestão do conhecimento, gerando subsídios para sustentabilidade e a descrição do cronograma que indica o início das atividades para maio de 2013. O certificado de parceria fornecido pelo DEA/MMA foi recebido posteriormente e somente a partir deste momento foram iniciadas as ações de montagem estrutural do espaço. Vale destacar que a Sala Verde Paraíba do Sul é a primeira do município de Volta Redonda e seu nome faz menção ao maior manancial de água doce da região Sul Fluminense que serpenteia pelos estados de São Paulo, Minas Gerais e Rio de Janeiro e que é responsável pelo abastecimento de cerca de 14,2 milhões de pessoas segundo o Comitê de Integração da Bacia do Rio Paraíba do Sul (CEIVAP, 2016), pelo fato de ter participação relevante no desenvolvimento daregião e de todo o Estado do Rio de Janeiro e finalmente à realidade negativa do vale em relação a ocorrência de acelerados processos erosivos, responsáveis pelo assoreamento de corpos hídricos, por eliminação das matas ciliares e pela deterioração da qualidade das águas do rio em tela. Ressalte-se que a criação da sala verde atrai muitas atenções no final do ano de 2014 por conta da grave crise hídrica nacional que assolou principalmente as regiões sudeste e sul e que mobilizou governo e sociedade para a redução do consumo, combate ao desperdício e adoção de medidas de caráter emergencial para superação deste nefasto quadro de insuficiência de um recurso estratégico para a sociedade, economia e natureza. 
Figura 01: Logo da Sala Verde Paraíba do Sul.

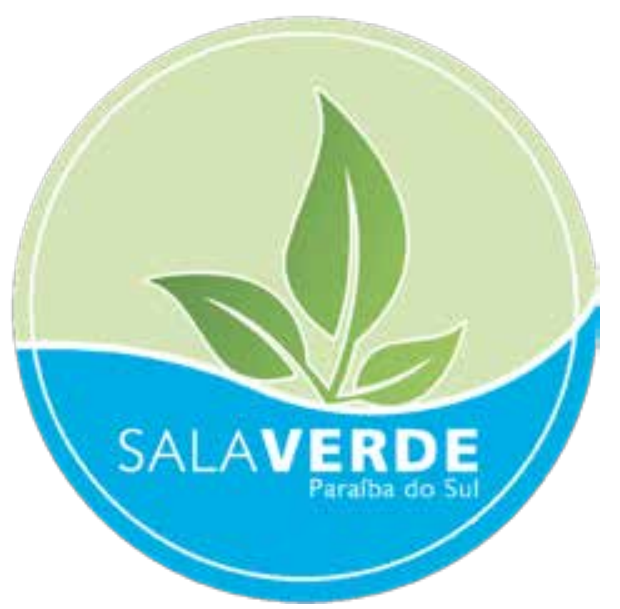

Fonte: Acervo Digital da Sala Verde.

\section{REVISÃo BIBLIOGRÁFICA}

Segundo o MMA (2016) uma sala verde é um espaço dedicado ao desenvolvimento de atividades de caráter educacional voltadas à temática socioambiental e cultural, atividades essas que visam contribuir e estimular a discussão crítica, a organização e o pacto social, o fortalecimento de identidades grupais, levando à formação de cidadãos mais informados, participativos e dedicados ao processo de construção de sociedades sustentáveis. Informa o MMA (2016) que atualmente existem 411 salas verdes no Brasil, distribuídas em todas as unidades da federação e que 292 permanecem em atividade, sendo que a maioria destes espaços encontra-se na região Sudeste com o total de 129, na região Sul são 88 salas cadastradas e no Nordeste são 81 unidades. A região Centro-Oeste possui 34 Salas Verdes e a Região Norte 25 espaços. Vale salientar que algumas salas verdes são itinerantes e desenvolvem seus respectivos projetos em espaços alternativos como, por exemplo: ônibus, trens, barcos e caminhões.

Figura 02: Vista geral da Sala Verde Paraíba do Sul.

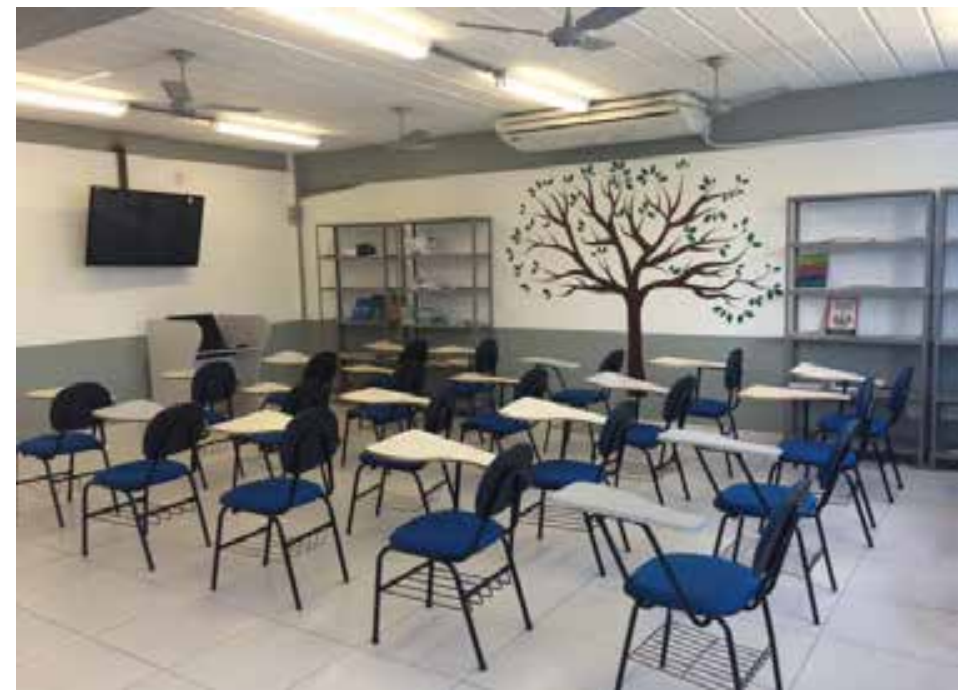

Fonte: Acervo digital da Sala Verde. 
Ainda, segundo o MMA (2016) a Sala Verde apresenta um grande potencial de delineamento e desenvolvimento de projetos, ações e programas educacionais e, portanto, pode cumprir umpapel articulador e integrador nas localidades onde se encontra, de modo a estar conectada com o que se pensa e se faz no município, sendo um espaço de promoção de sinergias entre instituições, pessoas, projetos, programas e ações, não só ambientais, mas também culturais, educacionais, e de ampliação da cidadania. A Educação Ambiental é desde 1981 um dos princípios ordenadores da Política Nacional de Meio Ambiente (PNMA) por força da lei federal $\mathrm{n}^{\circ}$ 6.938/81, art. $2^{\circ}$, X que textualmente pontua: educação ambiental a todos os níveis de ensino, inclusive a educação da comunidade, objetivando capacitá-la para participação ativa na defesa do meio ambiente. Conforme disposto na Política Nacional de Educação Ambiental (PNEA) preconizada pela lei federal nº 9.795/99 a educação ambiental é fruto dos processos por meio dos quais o indivíduo e a coletividade constroem valores sociais, conhecimentos, habilidades, atitudes e competências voltadas para a conservação do meio ambiente, bem de uso comum do povo, essencial à sadia qualidade de vida e sua sustentabilidade e neste contexto a sala verde é um espaço privilegiado para a formação do cidadão, considerando-se a sua formação socioambiental. O artigo 225, VI, da Constituição Federal da República Federativa do Brasil é outro dispositivo legal que igualmente destaca a importância da educação ambiental como política e incumbe o Poder Público de promover a mesma em todos os níveis de ensino e a conscientização pública para a preservação do meio ambiente. A Conferência Intergovernamental de Educação Ambiental realizada em Tbilisi (1977) sustenta através da recomendação ${ }^{\circ} 07$ que a educação ambiental tenha por finalidade criar uma consciência, comportamentos e valores com vistas a conservar a biosfera, melhorar a qualidadede vida em todas as partes e salvaguardar os valores éticos, assim como opatrimônio cultural e natural, compreendendo os sítios históricos, as obras de arte, os monumentos e lugares de interesse artístico e arqueológico, o meio natural ehumano, incluindo sua fauna e flora, e os assentamentos humanos.O princípio 10 da Declaração do Rio sobre Meio Ambiente e Desenvolvimento promulgada por ocasião da segunda Conferência das Nações Unidas de Meio Ambiente e Desenvolvimento (CNUMAD) realizada na cidade do Rio de Janeiro entre os dias 3 e 14 de junho de 1992 apregoa que no nível nacional, cada indivíduo terá acesso às informações relativas ao meio ambiente de que disponham as autoridades públicas, inclusive informações acerca de materiais e atividades perigosas em suas comunidades, bem como a oportunidade de participar de processos decisórios e que os Estados irão facilitar e estimular a conscientização e a participação popular, colocando as informações à disposição de todos. Castro \& Canhedo Jr. (2014) apregoam que a Educação Ambiental deve servir como um instrumento de participação da sociedade que vai possibilitar as pessoas incorporarem conhecimentos, valores, novas maneiras de ser, dentro de uma nova ética, tornando-as capazes de estabelecer uma relação de causa e conseqüência dos problemas ambientais, discutir questões, fixar prioridades, tomar decisões, exercer sua representatividade, buscando o desenvolvimento sustentável. Jacobi (2012) frisa que a criação de espaços de aprendizagem pode representar uma proposta pedagógico-metodológica que considera como contextos de vivência e convivência o cotidiano de uma realidade que se abre ao local e ao planetário e que se torna fundamental agregar novas formas de aprendizagem social, expansão do lócus de aprendizado e de interpretação do cotidiano e de arenas de negociação. O Código Municipal de Meio Ambiente de Volta Redonda, lei municipal nº 4.438/08, em seu art. $3^{\circ}$, X, estabelece em seu rol de objetivos que deve ocorrer a promoção da educação ambiental na sociedade e especialmente na rede pública de ensino. Fonseca \& Frenedozo (2012) enfatizam em seu trabalho investigativo que o desenvolvimento de projetos acerca de desmatamento e a questão do lixo urbano com escolas públicas na sala verde Frei Paulino localizada em Divinópolis/MG é uma boa estratégia para se fazer educação ambiental de modo prático. Correia (2012) conclui em sua pesquisa que as salas verdes são abrangentes em sua dimensão de política pública em educação ambiental, mas, que é um grande desafio a superação de dificuldades frente à dificuldade de articulação de parcerias para a potencialização de seus resultados. Milaré (2009) defende que a cidadania ambiental é enfatizada mediante o incentivo à participação individual e coletiva nos processos de preservação e recuperação da qualidade ambiental e que a Educação Ambiental é a grande estimuladora deste fortalecimento da consciência crítica. Conclui-se que é consenso entre os pesquisadores e na legislação ambiental a importância da Educação Ambiental como instrumento primordial para a conscientização e mobilização da sociedade planetária e sua mudança de postura de modo que os recursos ambientais existentes sejam devidamente protegidos e utilizados de maneira sustentável, de maneira que sua perenidade seja garantida. 


\section{AÇÕES DE EDUCAÇÃO AMBIENTAL DA SALAVERDE PARAÍBA DO SUL}

A partir de julho de 2014 é que se iniciam efetivamente as ações de cunho socioambiental da sala verde Paraíba do Sul e em 07 de abril de 2015 ocorre a cerimônia oficial de inauguração da mesma com a presença da Reitora do Centro Universitário citado anteriormente que sedia o espaço socioambiental em questão, da equipe responsável pela coordenação e atividades, coordenadores de cursos de graduação e demais autoridades convidadas. É indispensável destacar que a vigência da chancela da Sala Verde é indeterminada, desde que os resultados sejam apresentados anualmente e quando solicitados à instituição proponente através de relatórios e dados. As ações iniciais da Sala Verde Paraíba do Sul tiveram por objetivo maior a divulgação da mesma para a comunidade acadêmica da IES, buscando a parceria e cooperação do corpo discente para participação como monitores. Em seguida foi realizado contato com as Secretarias Municipais de Educação dos municípios vizinhos à Volta Redonda. O objetivo desta ação foi adquirir e arquivar o contato das direções gerais e pedagógicas de cada escola municipal para iniciar as ações de educação ambiental de caráter formal nas mesmas, assim como, convidar os alunos e professores para participarem de ações socioambientais no interior da própria sala. O contato com a Secretaria Estadual de Educação do Estado do Rio de Janeiro está em fase de realização, assim como o contato com as escolas privadas da região Sul Fluminense. Posteriormente foram contactadas as Secretarias Municipais de Meio Ambiente dos municípios vizinhos para divulgação da Sala Verde Paraíba do Sul e seus objetivos, bem como solicitar apoio e parcerias institucionais nas ações a serem realizadas. O público alvo da sala verde está representado por alunos, professores e funcionários do Centro Universitário, alunos das escolas públicas municipais e estaduais e privadas da região, professores de ensino fundamental, médio, técnico e superior, moradores do bairro Três Poços, onde se localiza o Campus da IES, ONG's que atuam na área de meio ambiente e órgãos públicos de proteção do meio ambiente. Vale mencionar que qualquer cidadão pode agendar uma visita a sala verde Paraíba do Sul bastando para isto contactar a Coordenação da Sala Verde que atende provisoriamente na secretaria do curso de Engenharia Ambiental e que atende pelo telefone (24) 3340-8400, ramal 8351 a partir das 13:00 horas e solicitar a marcação de um horário no turno matutino ou vespertino com a secretaria, estagiária da sala verde ou com os professores integrantes da equipe.

Figgura 03: Palestra realizada em 21/04/15 para alunos do Colégio Macedo Soares de Volta Redonda sobre o tema "Sustentabilidade".

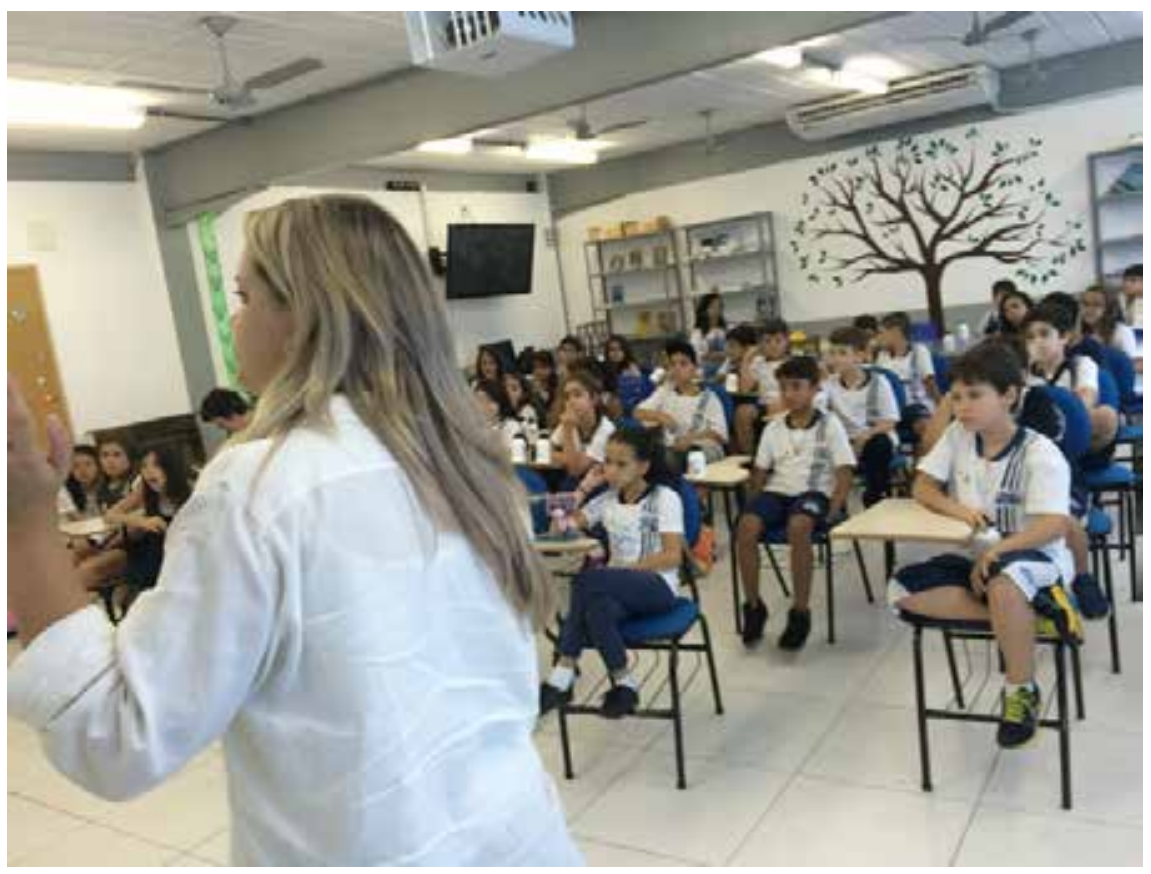

Fonte: Acervo digital da Sala Verde Paraíba do Sul. 
O ano de 2014 marca efetivamente o início das ações desenvolvidas pela sala verde Paraíba do Sul e neste lapso de tempo destacam-se as seguintes ações: Oficina de Reciclagem de Papel, Conhecendo a Sala Verde Paraíba do Sul, Comemoração do dia do Meio Ambiente no Colégio Anglo Americano de Volta Redonda, palestra sobre a importância da diversidade de insetos para o planeta e palestra sobre Responsabilidade Socioambiental, palestra "Eu sou o Meio Ambiente”, Oficina de Pallet e Cine Verde com a exibição de documentários e filmes educativos sobre a temática ambiental. Este mesmo ano é marcado pela estruturação física do espaço cedido pela instituição para sediar a sala e sua adequação para receber os visitantes, formação e entrosamento da equipe de docentes e discentes voluntários, adequação do Projeto Político Pedagógico apresentado ao Ministério do Meio Ambiente as peculiaridades da sala e preparação das futuras ações a serem realizadas. No ano em curso acontece no dia 05 de junho a apresentação de uma peça de teatro com tema ambiental, pelos alunos e monitores do curso de Engenharia Ambiental. O objetivo da ação foi levar a importância da educação ambiental para o cenário industrial. No período compreendido entre 01/08 à 01/12 a Sala Verde promoveu em conjunto com a Prefeitura de Pinheiral o plantio de espécies nativas da Mata Atlântica em áreas degradadas do Parque Cruzeiro, objetivando a estabilização do processo erosivo ora encontrado. Nos dias 04, 11, 18 e 25 de novembro o Secretário Municipal de Meio Ambiente de Pinheiral capacitou 23 pessoas entre alunos do UniFOA e moradores do bairro Três Poços de Volta Redonda para o controle de formigas e cupins. Já o ano de 2015 tem como principais realizações: 1- cinquenta e cinco alunos do Colégio Macedo Soares de Volta Redonda visitaram a sala em 21 de março e tiveram a oportunidade de conhecer mais sobre sustentabilidade ambiental e a mostra de produtos sustentáveis existentes na mesma (Figura 03); 2- dez alunos dos três módulos do curso de Técnico em Meio Ambiente oferecido pelo Colégio Estadual Rondônia de Volta Redonda visitaram a sala em quatorze de maio e assistiram a uma palestra sobre a importância dos insetos para o planeta; 3- em vinte e seis de junho a Sala Verde promove uma ação externa e realiza uma palestra e um teatro para cerca de 130 alunos do Colégio Anglo Americano em Volta Redonda por ocasião do dia mundial do Meio Ambiente; 4- no dia vinte e nove de julho a Sala Verde recebe o prefeito da cidade de Pinheiral, acompanhado de diretoras de escolas e creches municipais da mesma para a apresentação de projetos com vistas a melhoria da ventilação de uma creche, manejo de hortas vivas em várias escolas, reaproveitamento de água de chuva e construção de composteiras; 5- a sala verde participa efetivamente da Semana Acadêmica do Curso de Ciências Biológicas da IES nos dias 27 e 28 de julho, expondo todos os produtos confeccionados e ressaltando a importância da reciclagem e reaproveitamento de materiais para a proteção do meio ambiente; 6- nos dias 3 e 4 de agosto a Sala Verde promove a oficina denominada "Aquecipet”, onde os dezoito participantes receberam orientações para a construção de um aquecedor solar de água caseiro feito de garrafas pet e caixas de leite; 7- no dia sete de agosto a UniFOA convida a Sala Verde a participar do evento "UniFOA de Portas Abertas" com a montagem de um stand que tem por objetivo apresentar a instituição e a sala para cerca de 250 alunos de escolas públicas e privadas da região; 8- no dia trinta e um do mês de agosto os monitores da sala verde promovem uma palestra sobre "Responsabilidade Socioambiental" para doze alunos de vários cursos de graduação do UniFOA onde se enfatizou a utilização de várias estratégias com vistas a concretização da responsabilidade socioambiental pelos alunos em seu dia-a-dia; 9- a Sala Verde promove outra ação externa em 31 de agosto e profere uma palestra com o tema "Eu sou o Meio Ambiente" para 35 alunos do Colégio Municipal Walmir de Freitas de Volta Redonda; 10- a Sala Verde agenda e acompanha 22 alunos do Pré I-B do Colégio Anglo Americano de Volta Redonda ao Laboratório de Botânica e Zoologia do UniFOA no dia 19 de agosto onde os mesmos puderam conhecer mais de perto animais e plantas que conheciam apenas pela televisão, revistas e livros; 11- a Sala Verde oferece nos dias 5, 12, 19 e 26 de setembro a oficina para confecção de mobiliário de pallets para 18 moradores do bairro Nove de Abril localizado no município de Barra Mansa; 12- a Sala Verde agenda e acompanha 16 alunos do Pré I-A do Colégio Anglo Americano de Volta Redonda ao Laboratório de Botânica e Zoologia do UniFOA no dia 30 de agosto onde os mesmos puderam conhecer mais de perto animais e plantas que conheciam apenas pela televisão, revistas e livros; 13- a APAE de Volta Redonda oferece no dia 21 de outubro uma oficina de reciclagem de papel na Sala Verde para 32 alunos dos cursos de graduação do UniFOA e 14- a Sala Verde apresenta no dia 10 de novembro o Cine Verde para 31 quilombolas do Quilombo de Santana, localizado no município de Quatis. A partir das ações realizadas na Sala Verde e descritas aqui percebe-se que o espaço socioambiental ora avaliado tem potencial para se tornar um pólo de Educação Ambiental regional integrando todos os municípios do Sul Fluminense na promoção da EA de caráter formal e não-formal em ações internas e externas com o apoio e parcerias de órgãos públicos locais de meio 
ambiente como as Secretarias Municipais de Meio Ambiente, a Superintendência Regional do Instituto Estadual do Ambiente (INEA), Secretarias Municipais de Educação, escolas públicas e privadas, organizações não-governamentais de defesa do meio ambiente, empresas e demais instituições interessadas. A sala em questão possui uma estrutura física adequada com recursos audiovisuais operantes e suficientes para a difusão, discussão e capacitação em EA, inclusive com a produção de material didático, vídeos de curta duração e execução de projetos externos. Os elementos fundamentais integrantes de uma sala verde estão devidamente atendidos conforme recomendação expressa do MMA que lista o espaço, os equipamentos e recursos, a equipe responsável e Projeto Político Pedagógico como pilares essenciais ao pleno funcionamento da mesma. A sala verde Paraíba do Sul é hoje uma realidade solidificada e vem se tornando única, pois é condição sine qua non que sua configuração deve se basear e se ajustar por conta da identidade institucional e o público com que trabalha, dialogando com as potencialidades e particularidades locais e regionais. Os compromissos da instituição proponente junto a Departamento de Educação Ambiental do MMA vêm sendo atendidos em sua plenitude como a implementação, acompanhamento e avaliação do Projeto Político Pedagógico submetido e aprovado pelo edital; disponibilização e manutenção tempestiva do local/espaço que atenda os objetivos propostos, inclusive com o acesso garantido de pessoas portadoras de necessidades especiais; prestação de informações ao DEA por meio de relatório anual e indicação de equipe responsável pela coordenação, implementação e execução dos projetos desenvolvidos pela sala verde Paraíba do Sul. A interação da Sala Verde com a IES se encontra plenamente materializada pela adesão de vários alunos dos diversos cursos de graduação da Engenharia Ambiental, Engenharia Civil, Engenharia de Produção, Engenharia Elétrica, Ciências Biológicas, Design e Sistemas de Informação que tem participado regularmente das reuniões semanais que acontecem nas dependências da sala, capacitação de alunos visitantes de escolas agendadas, assessoramento para preparação das oficinas oferecidas, produção de material didático e palestras educativas, recepção de novos alunos interessados na monitoria e demais atividades desenvolvidas. Ressalte-se igualmente a compatibilidade e fidelidade do projeto apresentado com os Princípios da Política Nacional de Educação Ambiental (PNEA) e do Programa Nacional de Educação Ambiental (ProNEA, 2005), bem como a coerência entre objetivos, metas, metodologia, prazos e orçamento, incluindo sua viabilidade técnica.

\section{CONCLUSÕES}

A sala verde teve um total de 460 participantes em 2014 e 679 no ano de 2015 totalizando 1.139 pessoas atendidas nestes dois anos de realização do projeto. É mister que se estreitem os laços e contatos da Sala Verde Paraíba do Sul com os órgãos públicos de proteção ao meio ambiente, Secretarias Municipais de Educação dos municípios do Sul Fluminense, escolas públicas e privadas, organizações do Terceiro Setor e associações de moradores dos bairros adjacentes haja visto que os contatos preliminarmente feitos não surtiram os efeitos desejados para o estabelecimento de parcerias e convênios visando o alcance dos objetivos previamente estabelecidos. Nesse ínterim podemos mencionar a recente parceria firmada com a Comissão de Sustentabilidade das montadoras automobilísticas da região Sul Fluminense para desenvolvimento de projetos em conjunto visando o descarte de resíduos deste setor produtivo de maneira ambientalmente correta, no que tange a sua destinação. O sítio eletrônico da sala verde que está em processo de aprovação junto ao setor jurídico da IES e em construção pelo setor de informática será imprescindível para a divulgação maciça da mesma, contemplando no respectivo endereço eletrônico as ações desenvolvidas, o rol de atividades ofertadas junto à sociedade e o agendamento on-line de visitas e que após consolidado será de grande importância para a popularização da mesma. A transdisciplinaridade, interdisciplinaridade e a multidisciplinaridade preconizada pela lei federal n ${ }^{\circ}$ 9.795/99 (PNEA) tem sido alcançadas nas ações já concretizadas e em curso pelo envolvimento intenso de alunos dos mais diversos cursos de graduação oferecidos pela IES e por colaborar supletivamente na formação deste aluno/cidadão que assimila valores sociais, conhecimentos, habilidades, atitudes e competências voltadas para a conservação do meio ambiente, bem como em consonância com a lei federal no 9.394/96 de diretrizes e bases da Educação Nacional que prevêque a Educação Superior deve desenvolver o entendimento do ser humano e do meio em que vive; que a educação tem, como uma de suas finalidades, a preparação para o exercício da cidadania. Na análise criteriosa dos relatórios relativos aos anos de 2014 e 2015 percebe-se que as ações desenvolvidas pela Sala Verde Paraíba do Sul atingiram um público alvo heterogêneo, começando pela participação de alunos de diversos cursos de 
graduação da IES como monitores e auxiliares na preparação da sala para recepção aos eventuais visitantes, alunos do ensino fundamental e médio de escolas públicas e privadas, alunos de curso técnico, oficinas para moradores e alunos, parceria efetivada com uma prefeitura para desenvolvimento de projetos, capacitação de docentes para a Educação Ambiental e exibição de filmes educativos para comunidades tradicionais (quilombolas). 


\section{REFERÊNCIAS}

AB’ SÁBER, A. N. Os Domínios de Natureza no Brasil - Potencialidades Paisagísticas. São Paulo, Ed. Ateliê Editorial. 2003. 160p.

BRASIL. Constituição Federal de 05 de outubro de 1988. Brasília. Distrito Federal.

. Lei Federal nº 6.938/81. Política Nacional do Meio Ambiente, 1981. Brasília. Distrito Federal.

. Lei Federal no 9.394 de 20 de dezembro de 1996. Lei de Diretrizes e Bases da Educação Nacional, 1996. Brasília. Distrito Federal.

Lei Federal nº 9.795/99. Política Nacional de Educação Ambiental, 1999. Brasília. Distrito Federal.

Projeto político-pedagógico aplicado a Centros de Educação Ambiental e a Salas Verdes: manual de orientação. Brasília: Ministério do Meio Ambiente/Centro de Informação, Documentação Ambiental e Editoração, 2005. Disponível em: http://www.mma.gov.br/estruturas/educamb/arquivos/ceas_ppp.pdf. Acesso em: 23 jun. 2016.

CASTRO, M. L. \& CANHEDO Jr. S. G. Educação Ambiental como Instrumento de Participação.In:Philippi Jr. A. \&Pelicioni M. C. F. (orgs.) Educação Ambiental e Sustentabilidade. Editora Manole, $2^{\mathrm{a}}$ Edição, Barueri/SP, 2014. pp 465-475.

CORREIA, C. J. da SILVA. O projeto sala verde em União dos Palmares/AL: possibilidades e desafios de um centro de referência em Educação Ambiental. Revista Ambiente \& Educação. V.17, nº 2. 2012.

FONSECA, J. M.\&FRENEGOZO, R. Educação Ambiental desenvolvida pela Sala Verde Frei Paulino em Divinópolis/MG: projeto reciclando. Natureza online. 2012.

JACOBI, P. R. Governança ambiental, participação social e educação para a sustentabilidade. In:Philippi Jr. A.; Sampaio C. A. C \& Fernandes V. (orgs.) Gestão de natureza pública e sustentabilidade. Editora Manole, Barueri/ SP, 2012. pp 343-361.

Lei Municipal no 4.438/08. Dispõe sobre a criação do Código Municipal de Meio Ambiente de Volta Redonda. Volta Redonda/RJ.

MILARÉ, É. Direito do Ambiente: a gestão ambiental em foco. Editora Revista dos Tribunais. 6a Edição. 2009. 1343p.

http://www.mma.gov.br/educacao-ambiental/educomunicacao/salas-verdes\#oprojeto. (Site do Ministério do Meio Ambiente). Acesso em 21/06/16.

http://www.ceivap.org.br/usoagua.php. (Site do Comitê de Integração da Bacia do Rio Paraíba do Sul). Acesso em 24/06/16.

Princípio 10. Declaração do Rio sobre Meio Ambiente e Desenvolvimento. 1992.

www.portalvr.com (Site do Portal Institucional da Prefeitura Municipal de Volta Redonda/RJ) Acesso em 22/06/2016.

Recomendação nº 07 da Conferência Intergovernamental sobre Educação Ambiental aos Países Membros. 1977.

Relatórios digitais relativos aos anos de 2014 e 2015 fornecidos pela Coordenação da Sala Verde Paraíba do Sul. 